\title{
Combined treatment of dendritoma vaccine and low-dose interleukin-2 in stage IV renal cell carcinoma patients induced clinical response: A pilot study
}

\author{
YANZHANG C. WEI ${ }^{1,3}$, ROBERT P. STICCA ${ }^{1,4}$, JINHUA LI $^{1}$, LILLIA M. HOLMES ${ }^{1}$, KELLY E. BURGIN ${ }^{1}$, \\ SUSAN JAKUBCHAK $^{1}$, HILARY BOUTON-VERVILLE ${ }^{1}$, JANE WILLIAMSON $^{1}$, KAREN MEYER ${ }^{1}$, \\ LYNDON EVANS $^{2}$, JULIE MARTIN ${ }^{2}$, JOSEPH J. STEPHENSON ${ }^{2}$, STEVEN TROCHA ${ }^{1}$, \\ SAM SMITH $^{1}$ and THOMAS E. WAGNER ${ }^{1,3}$ \\ ${ }^{1}$ Oncology Research Institute and the Cancer Treatment Center, Greenville Hospital System, Greenville; \\ ${ }^{2}$ Cancer Center of the Carolinas, Greenville; ${ }^{3}$ Department of Biological Sciences, \\ Clemson University, Clemson, SC, USA
}

Received March 19, 2007; Accepted May 14, 2007

\begin{abstract}
Vaccination using dendritic/tumor cell hybrids represents a novel and promising cancer immunotherapy. We have developed a technology that can instantly purify the hybrids (dendritomas) from the fusion mixture of dendritic cells (DCs) and tumor cells. Our animal studies and a phase I study of stage IV melanoma patients demonstrated that dendritoma vaccination could be conducted without major toxicity and induced tumor cell-specific immunological and clinical responses. In this pilot study, ten stage IV renal cell carcinoma patients were studied. Dendritomas were made from autologous DCs and tumor cells and administered by subcutaneous injection. After initial vaccination, three escalating doses of IL-2 (3, 6, and 9 million units each) were followed within five days. This treatment regimen was tolerated well without severe adverse events directly related to the dendritoma vaccine. Most adverse events were related to IL-2 administration or pre-existing disease. Patient-specific immune responses were evaluated by flow cytometric measurement of interferon- $\gamma$-producing T-cells before and after vaccination in response to stimulation with tumor antigens. Nine out of nine patients eligible for the analysis showed an increase of IFN-
\end{abstract}

Correspondence to: Dr Thomas E. Wagner, Oncology Research Institute, Greenville Hospital System, 900 W. Faris Road, Greenville, SC 29605, USA

E-mail: twagner@ghs.org

Present address: ${ }^{4}$ Department of Surgery, University of North Dakota, School of Medicine and Health Sciences, 501 North Columbia Road, Grand Forks, ND 58203, USA

Key words: dendritoma, immunotherapy, renal cell carcinoma $\gamma$-expressing $\mathrm{CD}^{+} \mathrm{T}$ cells after vaccination(s); while five out of eight patients eligible for the analysis showed an increase of IFN- $\gamma$-expressing $\mathrm{CD}^{+} \mathrm{T}$ cells. Clinical responses were documented in $40 \%$ of the patients, three with stabilization of disease and one with a partial response documented by a reduction in tumor size. This pilot study demonstrated that dendritoma vaccines could be administered safely to patients with metastatic renal cell carcinoma, while producing both clinical and immunologic evidence of response.

\section{Introduction}

Current therapy for patients with renal cell carcinoma (RCC) is determined by the stage of disease at diagnosis. Surgery remains the principle option for RCC patients with local or regional disease. Surgical resection is fairly effective for early stage tumors with 5-year survival rates of $91-96 \%$ for stage I tumors and $69-95 \%$ for stage II tumors. Tumor recurrence rates vary by stage at diagnosis, with recurrent disease common in large tumors, when vascular invasion is present and when lymph nodes are involved at the initial diagnosis (stage II and III tumors). Reported recurrence rates are $20-30 \%$ for localized tumors. When recurrent disease is surgically resectable, moderate improvement in long-term survival can be achieved, but is dependent on several factors and can be as dismal as $0 \%$ or as good as $69 \%$ (1). Unfortunately, many patients with recurrent disease are not suitable candidates for surgery. Additionally, patients with recurrent RCC who can be resected often recur again with less chance of effective therapy at each episode of recurrence. Adjuvant therapy with chemotherapy and radiation has not been found to be effective in preventing recurrences and increases treatment toxicity (2-4).

Management of metastatic RCC (stage IV disease) carries a much poorer prognosis with no recognized effective treatment and long-term survival care. The average length of survival after diagnosis of metastatic RCC is $<10 \%$ at 5 years. Many types of therapy have been attempted for the management of 
Table I. Clinical characterization of patients.

\begin{tabular}{lccccc}
\hline Patient & Age/gender & $\begin{array}{c}\text { Date of } \\
\text { initial diagnosis }\end{array}$ & $\begin{array}{c}\text { Disease stage at } \\
\text { initial diagnosis }\end{array}$ & $\begin{array}{c}\text { Disease stage at } \\
\text { entering this trial }\end{array}$ & $\begin{array}{c}\text { Previous } \\
\text { therapies }\end{array}$ \\
\hline KM & $60 / \mathrm{M}$ & $03 / 1998$ & IV & IV & $\mathrm{S}, \mathrm{R}, \mathrm{Ch}$ \\
JT & $61 / \mathrm{M}$ & $07 / 1999$ & III & IV & $\mathrm{S}, \mathrm{Ch}$ \\
RR & $65 / \mathrm{M}$ & $05 / 1999$ & IV & IV & $\mathrm{Ch}, \mathrm{R}$, \\
RB & $57 / \mathrm{M}$ & $01 / 1999$ & III & IV & $\mathrm{S}, \mathrm{Ch}$, \\
WD & $65 / \mathrm{M}$ & $11 / 2000$ & IV & IV & $\mathrm{R}, \mathrm{S}$ \\
SF & $53 / \mathrm{M}$ & $10 / 2002$ & IV & IV & $\mathrm{S}$ \\
FD & $56 / \mathrm{M}$ & $03 / 1990$ & IV & IV & $\mathrm{S}, \mathrm{Ch}$, \\
NR & $55 / \mathrm{F}$ & $12 / 2002$ & IV & IV & $\mathrm{S}, \mathrm{Ch}$ \\
DB & $53 / \mathrm{M}$ & $04 / 2003$ & IV & IV & Ch, S \\
EG & 71/M & $12 / 2003$ & IV & IV & $\mathrm{S}, \mathrm{Ch}, \mathrm{R}$ \\
\hline
\end{tabular}

$\mathrm{S}$, surgery; R, radiotherapy; Ch, chemotherapy.

metastatic RCC; to date the options are still very limited (5). Clearly, more effective anti-tumor therapies are needed, both as an adjuvant for high-risk stage II and III tumors to prevent recurrence and for the management of metastatic disease in patients who present stage IV of the disease.

Various types of immunotherapeutic approaches have been used in the management of RCC. Some of these have had promising results (6), most of which have involved dendritic cells (DCs). DCs are professional antigen-presenting cells and have been studied as an anti-tumor immune response activator in many ways, including tumor antigen pulsing, tumor antigen gene transfection and DC/tumor cell fusion (7-10). Many clinical trials testing these strategies are either performed or are under investigation (11-13). In order to expand the idea of using DC/tumor fusion to stimulate antitumor immune response, we developed a technology with which uncultured tumor cells are fused with DCs and the hybrids, dendritomas, are instantly purified, so that the diversity of tumor antigens within the tumor cells is retained (14). Animal studies demonstrated that dendritomas are better anti-tumor immune response activators (15). A phase I study in stage IV melanoma patients indicated that dendritoma vaccination therapy is safe and stimulated tumor-specific immune responses and even in some cases had clinical responses (16). We used the same technology to expand the use of dendritoma vaccination therapy to RCC patients to evaluate for safety and immunological and clinical response. In this pilot study, ten patients with stage IV renal cell carcinoma were enrolled. Dendritomas were prepared from autologous DCs and tumor cells. Dendritomas were subcutaneously injected into the patients, followed by low doses of interleukin-2 (IL-2) therapy.

\section{Patients and methods}

Patient selection and study design. All patients had histologically confirmed metastatic renal cell carcinoma and an expected survival rate of 3-6 months. An ECOG performance status of 3 or lower was necessary to enter the trial. The inclusion criteria included adequate pulmonary function (FEV1 $>25 \%$ or DLCO $>25 \%$ predicted), adequate cardiac function, serum creatinine $<1.6, \mathrm{Hgb}>9.0, \mathrm{WBC}>3,000$, platelet count $>100,000$, and no prior history of a seizure disorder. Previous treatment with chemotherapy or immunosuppressive agents must have been discontinued at least 30 days prior to vaccination. Previous treatment with other forms of immunotherapy must have been discontinued six months prior to vaccination unless there was documented progression of the disease. Patients with CNS metastases were included and there were no limitations on tumor location or volume. It was necessary for each patient to have a tumor with a volume $>1 \mathrm{~cm}^{3}$ available for surgical excision (for vaccine preparation) and measurable residual disease for evaluation of response. Bidirectional measurements of residual disease were recorded from a maximum of four index lesions by direct measurement from computed tomography (CT) images for metastatic lesions. Tumor volumes were calculated from these measurements for comparison with post-treatment evaluations. Informed consent was obtained from each patient prior to entry into the trial. Human investigations were approved by the Institutional Review Committee of the Greenville Hospital System in accordance with an assurance filed with and approved by the Department of Health and Human Services. Production and use of vaccines in this protocol were approved and monitored by the Food and Drug Administration (IND 9519). The research design was similar to our previous studies (16).

Tumor and dendritic cell preparation. An autologous serum was used for preparation and maintenance of each patient's tumor cells and DCs. Two hundred milliliters of blood was withdrawn from the patient at least two weeks prior to initial vaccination. Serum was prepared from it using standard techniques. Prior to use, the serum was heat-inactivated by incubating at $56^{\circ} \mathrm{C}$ for $30 \mathrm{~min}$. This autologous serum comprising $10 \%$ by volume of the media was used for the maintenance of the patients' tumor cells and culture of DCs.

Mature DCs were generated from the patients' peripheral blood monocytes (PBMCs). Three hundred milliliters of sodium heparinized peripheral blood was obtained from each patient. PBMCs were isolated by Ficoll-Paque Plus gradient (Amersham Biosciences). Monocytes were then isolated from 
Table II. Summary of adverse events.

\begin{tabular}{lc}
$\begin{array}{l}\text { Body system } \\
\text { verbatim term }\end{array}$ & $\begin{array}{c}\text { No. of subjects } \\
(\mathrm{n}=10)\end{array}$ \\
\hline
\end{tabular}

Cardiovascular

Hypotension

Tachycardia

Eye

Blurred vision

Eye erythema

Gastrointestinal

Constipation

Stomatitis

Nausea

Vomiting

General disorders

Chills

Fever

Diaphoresis

Fatigue

Malaise

Inguinal pain

Chest pain

Pain (left side)

Shoulder pain

Toothache

Rigors

Dehydration

Edema

Lethargy

Chest wall fluid

Back pain

Pain

Rib pain

Tissue breakdown

Weakness

Hematopoietic/lymphatic

Anemia

Inguinal adenopathy

Hemorrhage

Thrombophlebitis

Infections

Infection

Pnuemonia

Urinary tract infection

Pharyngitis

Rhinitis

Injury

Femur fracture

Fall

Rib fracture

Metabolic/nutritional

Anorexia

Elevated alkaline phosphatase

Weight gain

Elevated creatinine

Hypercalcemia

Weight loss
Table II. Continued.

\begin{tabular}{lc}
\hline $\begin{array}{l}\text { Body system } \\
\text { verbatim term }\end{array}$ & No. of subjects \\
$(\mathrm{n}=10)$
\end{tabular}

Musculoskeletal

Arthralgia/myalgia 2

Joint stiffness 1

Cramping 2

Neurological

Weakness (left side) $\quad 1$

Dizziness 2

Leukoencephalopathy 1

Vocal cord paralysis $\quad 1$

Hemiparesis 2

Headache 1

Slurred speech 1

Psychiatric

Agitation $\quad 1$

Confusion 3

Hallucination $\quad 1$

Anxiety 3

Depression 2

Somnolence 1

Reproductive

Erectile dysfunction

Respiratory

Cough

Pulmonary embolism

Respiratory acidosis $\quad 1$

Dyspnea 3

Pulmonary edema 1

Pulmonary hypoxia 1

Wheezing 1

Skin

Epidermal cyst $\quad 1$

Facial flushing 1

Pruritis 1

Erythema 2

Flushing 2

Rash 1

Urinary

Dysuria 2

Urinary retention 1

Urinary frequency 1

the PBMCs by panning for 3-4 $\mathrm{h}$ in petri dishes. The purified monocytes were then cultured in complete DC medium (RPMI$1640,10 \%$ autologous serum, $800 \mathrm{U} / \mathrm{ml} \mathrm{GM-CSF}$ and $1000 \mathrm{U} / \mathrm{ml} \mathrm{IL}-4)$ at $37^{\circ} \mathrm{C}, 5 \% \mathrm{CO}_{2}$ for 8-10 days to generate dendritic cells. The DC medium was refreshed every three to four days. Dendritic cells were matured by adding $100 \mathrm{ng} / \mathrm{ml}$ of $\mathrm{TNF} \alpha$ and incubating for 24-48 h. Tumor tissue was obtained by excision of metastatic lesions in each patient. The tumor specimens were removed from the patients under sterile conditions and processed as follows. After separating fat and extraneous tissue from the tumor tissue, the tumor was cut into 
Table III. Clinical summary of patients.

\begin{tabular}{lcccr}
\hline Patient & $\begin{array}{c}\text { Date of first } \\
\text { vaccine }\end{array}$ & $\begin{array}{c}\text { No. of vaccines } \\
\text { (no. of dendritomas x 10 })\end{array}$ & $\begin{array}{c}\text { Clinical responses } \\
\text { (months) }\end{array}$ & $\begin{array}{c}\text { Days from first } \\
\text { vaccine to death }\end{array}$ \\
\hline KB & $03 / 22 / 01$ & $6(1,1,1,1,0.5,0.5)$ & SD (12) & 448 \\
JT & $04 / 05 / 01$ & $1(0.7)$ & PD & 67 \\
RR & $06 / 07 / 01$ & $3(1,1,0.5)$ & SD (6), PD & 334 \\
RB & $04 / 18 / 02$ & $2(0.26,0.65)$ & PD & 165 \\
WD & $05 / 09 / 02$ & $5(1,0.5,0.12,0.6,0.59)$ & SD (5) & 751 \\
SF & $01 / 24 / 03$ & $2(1,0.5)$ & PD & 159 \\
FD & $06 / 13 / 03$ & $3(0.53,0.54,1)$ & PD & 215 \\
NR & $03 / 26 / 04$ & $1(0.58)$ & PD & N/A \\
DB & $07 / 02 / 04$ & $3(0.16,0.34,0.31)$ & PD & N/A \\
EG & $01 / 07 / 05$ & $1(0.55)$ & 108 \\
\hline
\end{tabular}

SD, stable disease; PD, progressive disease; PR, partial response. aPatient withdrawn due to steroid treatment.

small pieces and put into a T75 flask containing $20 \mathrm{ml}$ digestion medium [RPMI-1640, $1.5 \mathrm{mg} / \mathrm{ml}$ collagenase type VIII (Sigma), and $26 \mu \mathrm{g} / \mathrm{ml}$ Pulmozyme (Genentech)]. This solution was rocked for $1-2 \mathrm{~h}$ at $37^{\circ} \mathrm{C}$ and the cell suspension was then filtered through a 40- $\mu \mathrm{m}$ cell strainer (Falcon cat. no. 2340). After two washes with PBS, the cells were re-suspended in ACK lysing solution $\left(0.15 \mathrm{M} \mathrm{NH}_{4} \mathrm{C} 1,1 \mathrm{mM} \mathrm{KHCO}, 0.1 \mathrm{mM}\right.$ $\mathrm{Na}_{2}$ EDTA, $\mathrm{pH}$ 7.3) and incubated for $5 \mathrm{~min}$ at room temperature to lyse the red blood cells. After centrifugation, the cells were re-suspended in complete tumor cell media (RPMI-1640, 10\% autologous serum, $200 \mu \mathrm{g} / \mathrm{ml}$ gentamicin) for fusion or in freezing medium (RPMI-1640, 10\% autologous serum, 10\% DMSO) for cryopreservation for later fusions.

Staining, fusion and sorting. Mature DCs were stained green using the PKH2-GL fluorescent dye (Sigma) and tumor cells, either fresh or frozen, were stained red using the PKH26-GL fluorescent dye (Sigma) according to the manufacturer's instructions. Before fusion, the tumor cells were irradiated with a single dose of $50 \mathrm{~Gy}$, sufficient to render the cell replication incompetent. The green DCs and the irradiated red tumor cells were fused at a 1:1 ratio according to a standard PEG fusion protocol. The fusion mixtures were incubated in complete DC medium overnight in a humidified $5 \% \quad \mathrm{CO}_{2}$ atmosphere at $37^{\circ} \mathrm{C}$. The next day the cells were harvested, analyzed, and hybrid cells (dendritomas) were sorted according to the presence of dual colors (red and green) using the FACS Vantage SE (BD Biosciences).

Treatment. The number of dendritomas in each patient's vaccine varied from $155,000-1,000,000$ depending on the yield from the culture and fusion process. After irradiation at $100 \mathrm{~Gy}$, these dendritomas were re-suspended in 1-1.5 $\mathrm{ml}$ of normal saline (NS) and injected subcutaneously into the patient immediately adjacent to a lymph node basin. One day after dendritoma injection, IL-2 was administered by a subcutaneous injection with escalating doses (3, 6, and 9 $\mathrm{mIU} / \mathrm{m}^{2} /$ day) within five days. Each patient was premedicated $1 \mathrm{~h}$ prior to IL-2 injection with claritin $(10 \mathrm{mg})$, celebrex $(100 \mathrm{mg})$ or relafen $(1000 \mathrm{mg})$. Patients were re- vaccinated every three months depending on the availability of dendritomas and tumor cells. Re-vaccination was administered in a similar fashion as the initial vaccination with the exception that IL-2 was not given. Patients received a maximum of six vaccinations depending on their disease progression and the availability of the vaccine.

Follow-up. All patients were monitored closely at prescribed intervals throughout recurrence or progression, if present, until death. They were evaluated closely for pulmonary, renal, hepatic, gastrointestinal, cardiac, autoimmune, or other toxicities in addition to evidence of regression or progression of their index lesions. Immediately post vaccination, patients were followed-up at days 1 and 3 with complete blood counts $(\mathrm{CBC})$, creatinine levels, liver function tests (LFTs), and clinical examinations. The two-week and one-month followups included a clinical examination, CBC, electrolytes, BUN, and creatinine levels. CT scans of the head, chest, abdomen, and pelvis were obtained at 3-month intervals prior to revaccination.

$I F N-\gamma$ assay. Before the first vaccine, two and four weeks after the first vaccine, and one and four weeks after re-vaccination, blood samples were taken from the patients and were used to perform the intracellular interferon- $\gamma$ analysis using anti-human IFN- $\gamma$ FastImmune ${ }^{\mathrm{TM}}$ CD4 or CD8 intracellular cytokine detection kit (BD Biosciences). Briefly, $1.5 \mathrm{ml}$ of whole blood from each sample was distributed into three conical tubes (each $0.5 \mathrm{ml}$ ) labeled as unactivated (negative control), activated (experiment), and SEB (Staphylococcal enterotoxin $B$, positive control), respectively. Five microliters of CD28/CD49 from the BD FastImmune intracellular cytokine detection kit was then added into each tube. Five microliters of autologous tumor lysates or 2 microliters of SEB were added into the 'activated' tube and the 'SEB' tube, respectively. The tubes were vortexed and incubated at $37^{\circ} \mathrm{C}$ for $2 \mathrm{~h}$. Ten microliters BFA solution from the kit was added into each tube and the tubes were incubated for a further $4 \mathrm{~h}$. After the 4-h incubation period, $50 \mu 1$ EDTA solution was added into each tube. The red blood cells in the tubes were 
A
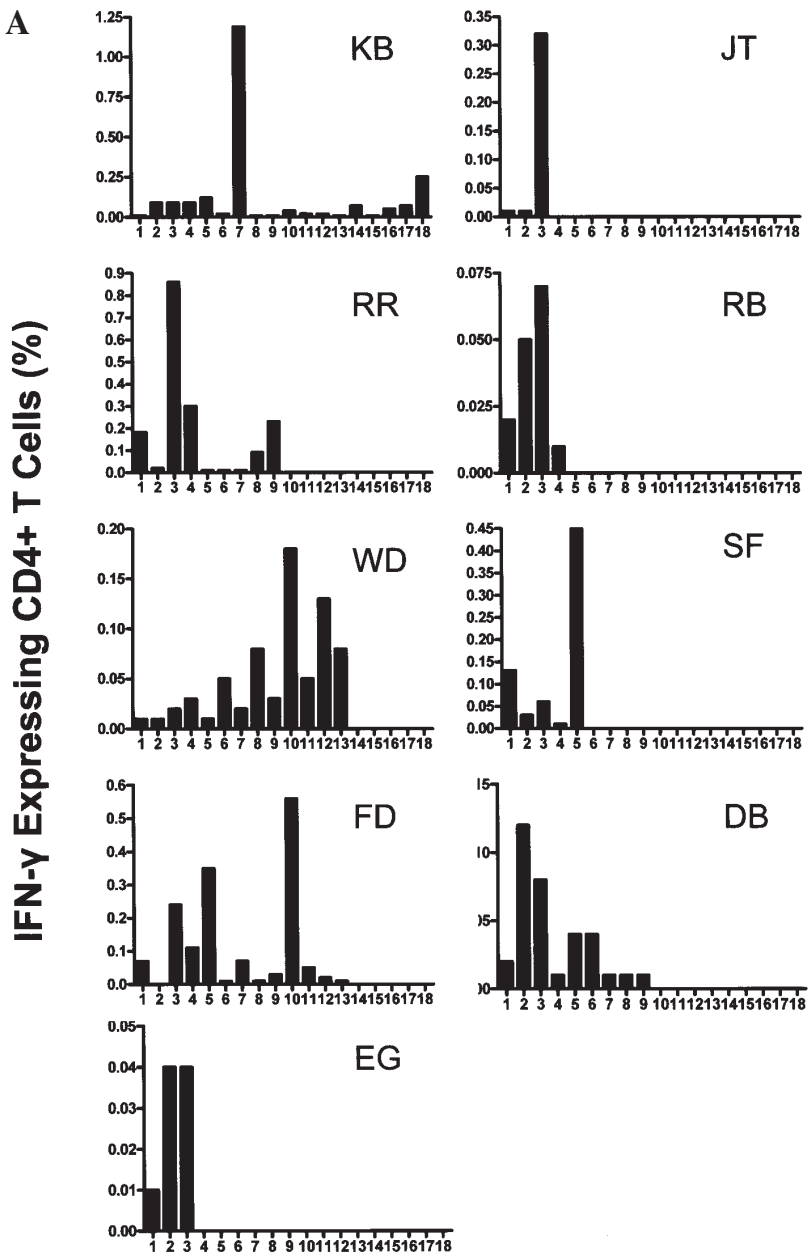

$\mathrm{DB}$
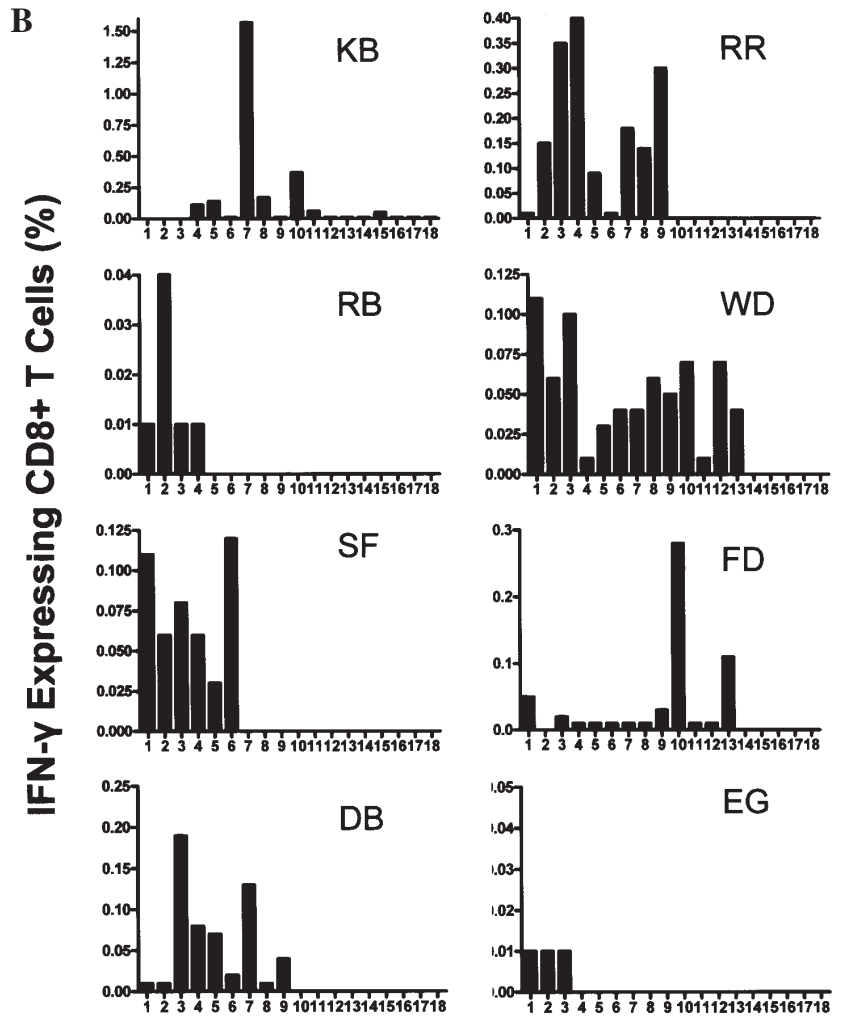

Figure 1. Intracellular IFN- $\gamma$ assay. Blood samples were obtained from patients at different time points and used to detect CD4+ $(\mathrm{A})$ or $\mathrm{CD} 8^{+}(\mathrm{B})$ and $\mathrm{CD} 69^{+} \mathrm{T}$ lymphocytes expressing IFN- $\gamma$ using human IFN- $\gamma$ FastImmune kit (BD Biosciences). The numbers under the X axis are (1): prior to vaccine no. 1 ; (2): two weeks post vaccine no. 1 ; (3): four weeks post vaccine no. 1; (4): prior to vaccine no. 2 ; (5): one week post vaccine no. 2 ; (6): four weeks post vaccine no. 2 ; (7): prior to vaccine no. 3 ; (8): one week post vaccine no. 3 ; (9): four weeks post vaccine no. 3 ; (10): prior to vaccine no. 4; (11): one week post vaccine no. 4; (12): four weeks post vaccine no. 4; (13): prior to vaccine no. 5; (14): one week post vaccine no. 5; (15): four weeks post vaccine no. 5; (16): prior to vaccine no. 6 ; (17): one week post vaccine no. 6 ; (18): four weeks post vaccine no. 6.

lysed by adding $5 \mathrm{ml}$ lysing solution (from the kit) into each tube and were incubated at room temperature for $10 \mathrm{~min}$. After two washings with staining buffer $(0.1 \%$ BSA and $0.1 \%$ $\mathrm{NaN}_{3}$ PBS), the cells were stained with anti-CD4-PerCPCy5.5 or anti-CD8-PerCP-Cy5.5 and CD69-PE antibodies. After surface marker staining, the cells were permeabilized and stained with anti-IFN- $\gamma$-FITC antibody. The cells were then analyzed on a FACSCalibur with CellQuest software (BD Biosciences). Because of the addition of marker CD69, an activated $\mathrm{T}$ cell marker, we were able to analyze IFN- $\gamma$ production by activated $\mathrm{CD} 4^{+} \mathrm{T}$ cells and $\mathrm{CD} 8^{+} \mathrm{T}$ cells.

For the IFN- $\gamma$ ELISA assay, PBMCs were isolated from the patients' peripheral blood and cultured $\left(1.7 \times 10^{6}\right.$ cells/well $)$ for 3 days in the presence of autologous tumor lysate. One milliliter of supernatant was collected from each well and used for the IFN- $\gamma$ ELISA assay with the OptEIA human IFN-ELISA kit II (BD, no. 550612).

\section{Results}

Vaccine production and safety. The study enrolled ten stage IV renal cell carcinoma patients (Table I). A total of 21 dendritoma vaccine productions were performed using the patients' blood-derived DCs and tumor cells. A total of 27 vaccinations were administered to the patients. The initial vaccination for each patient was followed by a low-dose IL-2 therapy. Safety data are summarized in Table II. The cumulative summary of adverse events (AEs) from the study showed that fever $(90 \%)$, nausea $(70 \%)$, vomiting $(60 \%)$, anemia (60\%), and chills $(60 \%)$ were the most common AEs experienced by the patients. Other commonly experienced AEs included unspecified pain (50\%), stomatitis (40\%), and weight loss $(40 \%)$. Most of these AEs were either disease related or IL-2 related. There was no serious adverse event (SAE) that was directly related to the dendritoma vaccine. The two most common AEs (fever and chills) are well-recognized side effects of IL-2 administration.

Dendritoma/IL-2 treatment increases tumor cell-specific IFN- $\gamma$ expressing $T$ cells. IFN- $\gamma$-expressing $\mathrm{CD}^{+}$or $\mathrm{CD}^{+} \mathrm{T}$ lymphocytes were measured in PBMCs isolated from the patients' pre-vaccination, 1, 2, and 4 weeks post first vaccination and 1 and 4 weeks post re-vaccinations using the FastImmune CD4 or CD8 intracellular cytokine detection kits with anti-human IFN- $\gamma$. The PBMCs were unstimulated as a negative control, stimulated with patients' autologous tumor 


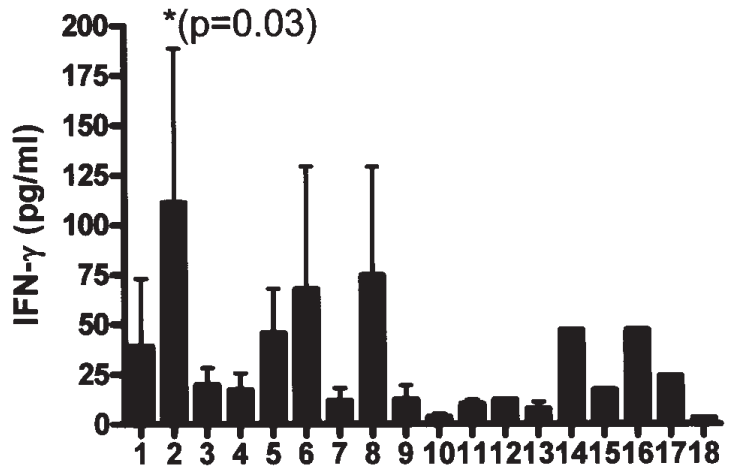

Figure 2. IFN- $\gamma$ production by patients' PBMCs. PBMCs were isolated from patients' peripheral blood and cultured (1.7 $\times 10^{6} /$ well, 24-well plate). At day $3,1 \mathrm{ml}$ of supernatant was collected from each well and used for the IFN- $\gamma$ ELISA assay. 1: prior to vaccine no. 1 (7); 2: two weeks post vaccine no. 1. (7); 3: four weeks post vaccine no. 1 (9); 4: prior to vaccine no. 2 (6); 5: one week post vaccine no. 2 (5); 6 : four weeks post vaccine no. 2 (5); 7: prior to vaccine no. 3 (4); 8: one week post vaccine no. 3 (3); 9: four weeks post vaccine no. 3 (3); 10: prior to vaccine no. 4 (2); 11: one week post vaccine no. 4 (2); 12: four weeks post vaccine no. 4 (2); 13: prior to vaccine no. 5 (2); 14: one week post vaccine no. 5 (1); 15: four weeks post vaccine no. 5 (1); 16: prior to vaccine no. 6 (1); 17: one week post vaccine no. 6 (1); 18 : four weeks post vaccine no. 6 (1).

lysate, or stimulated with staphylococcal enterotoxin B (SEB) as a positive control. The analysis of $\mathrm{CD}^{+}$or $\mathrm{CD}^{+} \mathrm{T}$ cells expressing IFN- $\gamma$ was performed on a FACSCalibur. Nine out of nine patients eligible for the analysis showed increases in IFN- $\gamma$-expressing $\mathrm{CD}^{+}{ }^{+} \mathrm{T}$ cells at least at one test point (Fig. 1A), while five out of eight patients eligible for the analysis showed increases in IFN- $\gamma$-expressing $\mathrm{CD}^{+} \mathrm{T}$ cells at least at one test point (Fig. 1B). The IFN- $\gamma$ ELISA assay also indicated an increased IFN- $\gamma$ expression by PBMCs isolated from the patients (Fig. 2). A pooled IFN- $\gamma$ expression by PBMCs isolated from patients two weeks post initial vaccination was significantly higher than that of the patients before vaccination $(\mathrm{p}=0.03)$, while the IFN- $\gamma$ levels expressed by $\mathrm{PBMCs}$ from patients 4 weeks after revaccination no. 2 and one week after re-vaccination no. 1 were higher than those before the initial vaccination, but not statistically significant.

Clinical responses. At the time of the preparation of this manuscript, eight patients enrolled in this study were deceased. One of the remaining patients has progressive disease. Another patient was withdrawn from the study due to a medical problem requiring steroid treatment, a prohibited concomitant medication for this study. The two patients are being followed-up for survival. The clinical responses are summarized in Table III. After dendritoma vaccination and IL-2 therapy, one patient had a partial response and the disease of three other patients' was stabilized. At the time of the first revaccination, three months after the initial vaccination, patient WD developed a partial response. Consecutive CT scans showed that his right upper lobe nodule was stabilized and the right renal bed lesion shrank. At the time of the third revaccination, about eight months after the initial vaccination, the patient's target lesion sum was $5.2 \mathrm{~cm}$, a $37.5 \%$ decrease. Patient KB's disease was stabilized after the initial vaccination and lasted for $\sim 12$ months. Patients RR and SF also developed stabilized disease for 6 and 5 months, respectively.

\section{Discussion}

It is important to monitor the immune responses such as CTL activity, increased IFN- $\gamma$-expressing $\mathrm{T}$ cells, etc. after the administration of immunotherapies in clinical studies $(17,18)$. We chose to use the change in IFN- $\gamma$-expressing $\mathrm{T}$ cells including $\mathrm{CD}^{+}$and $\mathrm{CD}^{+}$cells as an indicator of immune response in this study. All of the patients eligible for the analysis showed an increased number of IFN- $\gamma$-expressing $\mathrm{CD}^{+} \mathrm{T}$ cells after vaccination at least at one time point (Fig. 1A). However, only five of eight patients eligible for the analysis showed increased number of IFN- $\gamma$-expressing $\mathrm{CD}^{+} \mathrm{T}$ cells after vaccination at least at one point in time (Fig. 1B). To note, our best clinical responder, patient WD who achieved a partial clinical response for six months, did not show an increase in IFN- $\gamma$-expressing $\mathrm{CD} 8^{+} \mathrm{T}$ cells although his number of IFN- $\gamma$-expressing $\mathrm{CD}^{+}{ }^{+} \mathrm{T}$ cells increased compared to that of pre-vaccination. Although more data are needed to make an informative conclusion, we would like to point out that commonly used immune response measurements may not be good representatives of clinical responses for immunotherapeutic studies. This agrees with other studies $(11,18)$. Therefore, the focus should be on clinical responses instead of so-called immune responses for immunotherapeutic trials.

The results presented in this paper illustrate a unique and promising immunotherapy for renal cell carcinoma and other cancer patients. However, several challenges need to be overcome before the therapy can be available to more patients. First, the manufacturing of the dendritoma vaccine is complicated. It requires high numbers of autologous DCs and tumor cells, which are at times difficult to obtain. The efficiency of fusion between DC and tumor cells and the sorting of fused hybrids is relatively low. Fortunately, procedures that can generate high numbers of DCs have been reported $(19,20)$. The fusion efficiency can also be improved by other fusion methods such as electroperation $(21,22)$ or different fusion conditions (23). The combination of a centralized manufacturing facility and improved conditions for DC culture and fusion may make the dendritoma vaccine more effective and available for more cancer patients. Secondly, IL-2 was used as an adjuvant to boost the immune response after the initial dendritoma vaccination. Although its boost effect is clear, IL-2 always causes severe adverse effects. Therefore, other agents with no or less side effects need to be tested. Thirdly, patients enrolled in this study were late-stage renal carcinoma patients whose immune system had been severely compromised by the disease development. There are many possible explanations why tumor vaccines may be less effective in patients with large tumor burdens. These include high amounts of circulating tumor antigen which can block effective immune responses, depressed immune function due to tumor load, nutritional depletion due to tumor cachetic factors as well as others. Therefore, we speculate that the dendritoma vaccine may be more effective for patients who have minimal tumor burden after initial surgical 
resection. The optimal patients for vaccine therapy might be those who are macroscopically disease-free after tumor resection with minimal residual microscopic disease.

\section{Acknowledgements}

We owe thanks to Brandy Jacks and Sabrina Madden for their professional nursing skills and to Lakendra Workman for her administrative work. This study was partially supported by an NIH grant (R21 CA101224-02).

\section{References}

1. Eggener SE, Yossepowitch O, Pettus JA, et al: Renal cell carcinoma recurrence after nephrectomy for localized disease: predicting survival from time of recurrence. J Clin Oncol 24: 3101-3106, 2006.

2. Drucker BJ: Renal cell carcinoma: current status and future prospects. Cancer Treat Rev 31: 536-545, 2005.

3. Lam JS, Belldegrun AS and Figlin RA: Adjuvant treatment for renal cell carcinoma. Expert Opin Pharmacother 7: 705-720, 2006.

4. Mickisch GH and Mattes RH: Combination of surgery and immunotherapy in metastatic renal cell carcinoma. World J Urol 23: 191-195, 2005.

5. Motzer RJ, Michaelson MD, Redman BG, et al: Activity of SU11248, a multitargeted inhibitor of vascular endothelial growth factor receptor and platelet-derived growth factor receptor, in patients with metastatic renal cell carcinoma. J Clin Oncol 24: 16-24, 2006.

6. Gouttefangeas C, Stenzl A, Stevanovic S, et al: Immunotherapy of renal cell carcinoma. Cancer Immunol Immunother 56: 117-128, 2007.

7. Rosenblatt J, Kufe D and Avigan D: Dendritic cell fusion vaccines for cancer immunotherapy. Expert Opin Biol Ther 5: 703-715, 2005.

8. Den Brok MH, Nierkens S, Figdor CG, et al: Dendritic cells: tools and targets for antitumor vaccinations. Exp Rev Vaccines 4: 699-710, 2005

9. Ribas A: Genetically modified dendritic cells for cancer immunotherapy. Curr Gene Ther 5: 619-628, 2005.

10. Farkas A, Conrad C, Tonel G, et al: Current state and perspectives of dendritic cells vaccination in cancer immunotherapy. Skin Pharmacol Physiol 19: 124-131, 2006.
11. Avigan D, Vasir B, Gong J, et al: Fusion cell vaccination of patients with metastatic breast and renal cancer induces immunological and clinical responses. Clin Cancer Res 10: 4699-4708, 2004.

12. Sheng KC, Pieterxz GA, Wright MD, et al: Dendritic cells; activation and maturation - applications for cancer immunotherapy. Curr Med Chem 12: 1783-1800, 2005.

13. Berntsen A, Geertsen PF and Svane IM: Therapeutic dendritic cell vaccination of patients with renal cell carcinoma. Eur Urol 50: 34-43, 2006.

14. Holmes LM, Li J, Sticca RP, et al: A rapid, novel strategy to induce tumor cell-specific cytotoxic T lymphocyte (CTL) responses using instant dendritomas. J Immunother 24: 122-129, 2001.

15. Li J, Holmes LM, Franek KJ, Burgin KE, et al: Purified hybrid cells from dendritic cell and tumor cell fusions are superior activators of antitumor immunity. Cancer Immunol Immunother 50: 456-462, 2001.

16. Wei Y, Sticca RP, Holmes LM, et al: Dendritoma vaccination combined with low dose interleukin-2 in metastatic melanoma patients induced immunological and clinical responses. Int J Oncol 28: 585-594, 2006.

17. Spagnoli GC, Adamina M, Bolli M, et al: Active antigen-specific immunotherapy of melanoma: from basic science to clinical investigation. World J Surg 29: 692-699, 2005.

18. Lucignani G, Ottobrini L, Martelli C, et al: Molecular imaging of cell-mediated cancer immunotherapy. Trends Biotechnol 24: 410-418, 2006.

19. Wan $\mathrm{H}$ and Dupasquier M: Dendritic cells in vivo and in vitro. Cell Mol Immunol 2: 28-35, 2005.

20. Peng JC, Thomas R and Nielsen LK: Generation and maturation of dendritic cells for clinical application under serum-free conditions. J Immunother 28: 599-609, 2005.

21. Lindner M and Schirrmacher V: Tumor cell-dendritic cell fusion for cancer immunotherapy: comparison of therapeutic efficiency of polyethylene-glycol versus electro-fusion protocols. Eur J Clin Invest 32: 207-217, 2002.

22. Siders WM, Vergilis KL, Johnson C, et al: Induction of specific antitumor immunity in the mouse with the electrofusion product of tumor cells and dendritic cells. Mol Ther 7: 498-505, 2003.

23. Linuma H, Okinaga K, Fukushima R, et al: Superior protective and therapeutic effects of IL-12 and IL-18 gene-transduced dendritic neuroblastoma fusion cells on liver metastasis of murine neuroblastoma. J Immunol 176: 3461-3469, 2006. 